\title{
Visual Studio Code for Activity Monitoring Interface
}

\author{
Nyayu Latifah Husni ${ }^{1, *}$ Putri Adelia Rahma Sari ${ }^{2}$ Tresna Dewi ${ }^{3}$ Ade Silvia \\ Handayani ${ }^{4}$ Devi Sartika ${ }^{5}$ Akhmad Mirza ${ }^{6}$
}

\author{
${ }^{1-6}$ State Polytechnic of Sriwijaya \\ ${ }^{*}$ Corresponding author. Email: nyayu_latifah@polsri.ac.id
}

\begin{abstract}
The Activity monitoring system is urgently needed due to the development in the infrastructure is not equal to the human consciousness to protect and keep it. This system can be used to prevent human to destroy the environment. However, how to design the device interface that can be used to monitor the activity from further place using IoT technology is still a big problem. Therefore, this paper presents the design of the interface used for the activity monitoring system based on Visual Studio Code. The proposed interface will consist of some menus, such as: Home, Activities, and Environment. The activities and the environment menu consist of 2 locations, namely: Sekanak mini garden and Sekanak River. From this activity's menu, it will be displayed the amount of the activities of littering and the normal one in those two locations, while from the environment menu, it can be seen the temperature, humidity, water level, and air quality in its surrounding. The experiment of this interface has shown that it can work well in monitoring the activity and the environment well. All the parameters being monitored can be displayed by the interface.
\end{abstract}

Keywords: Sekanak River, Sekanak Mini Garden, Monitoring System, Interface, IoT, Visual Studio Code.

\section{INTRODUCTION}

Technological developments are increasing every year and will continue for the next 5 years or more, this causes more and more countries to compete to bring up a new and leading innovation accompanied by sophisticated technology. Apart from that, the faster development process is one of the supporting factors for countries that can adapt to the development of technology and the internet. Internet of Things (IoT) is widely used in connecting devices and collecting data information. Internet of Things is used with IoT frameworks to handle and interact with data and information. In the system, users can register their sensors, create streams of data, and process information. IoT is applicable in various methodologies of agriculture. Applications of IoT are Smart Cities, Smart Environment, Smart Water, Smart Metering, Security and Emergency, Industrial Control, Smart Agriculture, Home Automation, e-Health, etc. 'Internet of Things is based on the device which is capable of analyzing the sensed information and then transmitting it to the user. then transmitting it to the user. [1]

The infrastructure development that has been carried out by the government to make people more comfortable in their activities. However, the development is not maintained well. There are many activities that can harm the surrounding environment. Thus, a monitoring system that can monitor the destructive habit is needed. This paper present the interface using Visual Studio Code for an IoT-based that can be used in the Activity Monitoring system. In the process of making a website, this system uses various programming languages, such as Java, Javascript, HTML, and MySQL. It is intended for creating a website interface that suits the system's needs. Visual Studio has a very lightweight cross-platform, it can be used by anyone to create or build and even run Web applications. Its features will continue to grow along with the development of the Visual Studio 
code version. The development of the Visual Studio Code version is also carried out periodically every month, and this is what makes Visual Studio Code compared to other text editors be superior. Visual studio code for the activity monitoring system has become a very important requirement for human life today. Where all human activities are carried out with the help of such a Web application.

The activity monitoring system proposed will give an efficient data collection. It can be used optimally by using Visual studio code as a Web that can display the results of littering detection. Besides that, it can also be used to detect the environmental conditions, such as, temperature, humidity, air quality, and water level. This system website is very helpful and useful in the process of monitoring human activity and environmental conditions, so that it is not necessary for human to go to the spots to monitor it directly. The activity can be monitored in further way. In addition, the tool can be accessed easily via the web.

This system creates a condition where people must be aware, willing, and prevent problems from the environment and get used to not doing activities that can harm the environment, namely littering.

\section{OVERVIEW}

Activity monitoring systems are placed in two corners of the Palembang city location, namely the Sekanak River and 27 Ilir Park. It is intended to monitor human activities in the form of littering and environmental conditions, such as: temperature, humidity, air quality, and water level. This system will detect human who has littered the location and it will also detect the environmental conditions using sensors that have been installed on the system. The results of the detection of this system can be seen on the device, i.e., it appears on the LCD layer of the system. Apart from that, the system can also be monitored through a website that has been provided by the system. Thus, it can make it easier for users to see the results of system detection anywhere and anytime. The website that has been designed can be used using mobile phones, laptops, computers, and PCs.

To make this website, it is used HTML and MySQL languages with visual studio code applications, HTTP and JavaScript Object Notation (JSON), as a form of a data communication method in storing data and receiving data. It runs with the concept of API (Application programming interface) that functions as the entrance to the server so that when the user enters the server, the API (Application programming interface) will be the connector to the server. In this activity monitoring system, a Mini-PC connected to a modem device as an internet connection is used. This server can display the detection results that can be detected by the system, namely detecting littering activities and detecting environmental conditions at the 2 locations in the form of temperature, humidity, air quality, and river water level that is located at Sekanak River.

In this research, it is used the web platform www.aidevsrg.com domain. It can monitor all installed systems so that they can be accessed via devices, such as mobile phones, laptops, computers, and PCs. Users must install a browser to be able to access the website link and connect to the internet so that users can see through their devices directly and can see the results of system activity detection and changes in temperature, humidity, air quality, and water level.

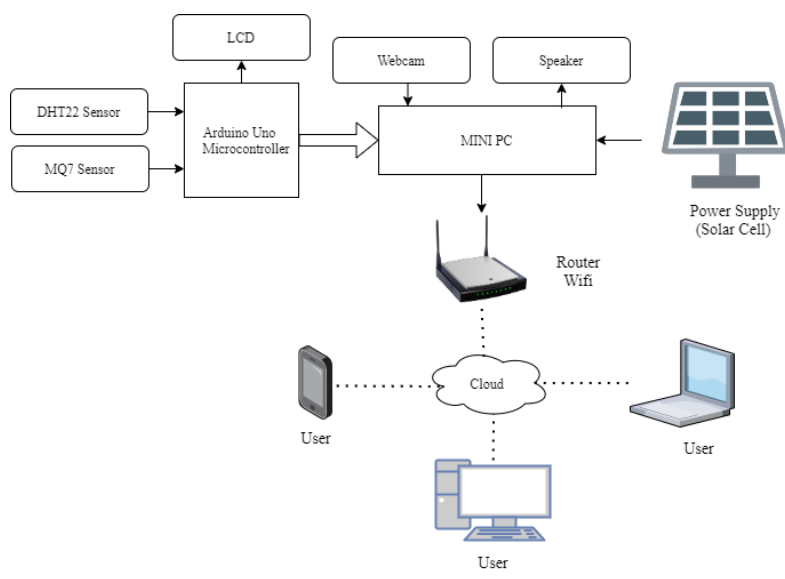

Figure 1 Block Diagram of activity monitoring system for 27 Ilir mini garden

Based on the block diagram in Figure 1, some inputs in the system will send data to the server. The inputs come from some sensors, such as: 1) the MQ7 sensor, as an air quality detector; 2) a DHT22 sensor, as a temperature and humidity detector; and 3) a webcam, as a camera that will capture images of human activities in the form of littering. All input that enters the system will send the detection results to the server so that the server will receive the data and display it on the dashboard page of the website. The results of changes from the detection can be seen directly as output in the system. Apart 
from that, the output of this system can also make a sound as a notification for people who have been detected carrying out littering activities. It is also displayed by an LCD layer installed on the system.

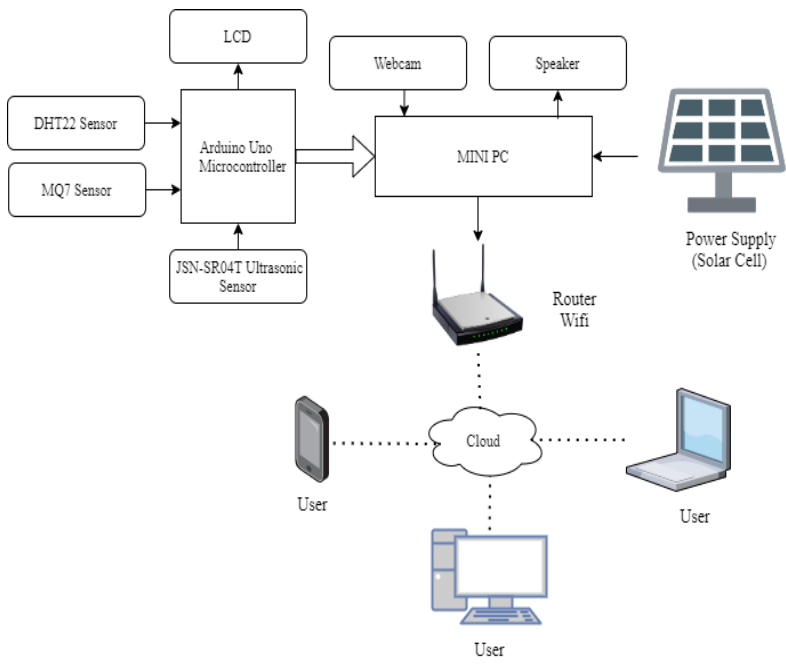

Figure 2 Block Diagram of activity monitoring system for sekanak river.

Figure 2 shows the Block Diagram of the activity monitoring. It is almost the same with the block diagram in Figure 1. However, there is an additional input, namely an ultrasonic waterproof sensor that functions as a river water level detector. It is intended to prevent flooding in the surrounding area. The sensor detection results will be sent to the server and displayed on the system's website page.

\section{METHODOLOGY}

\subsection{Website Design}

\subsubsection{Planning}

To produce a good website so that the system can run well, careful planning is needed. One of them is conducting a feasibility study of the methods used in the data collection process. Feasibility studies in this research includes some steps, i.e., data collection methods, data sources, data collection techniques, and data analysis techniques.

\subsubsection{Data Collection Methods}

The data collection process is conducted by identifying the problem and making a design flow that will be implemented. It is needed to ensure that there is no error in the manufacturing process. The planning process for making a website in this research is shown in the Figure 3. It is a planning methodology diagram that based on the SDLC (Software Development Life Cycle) method.

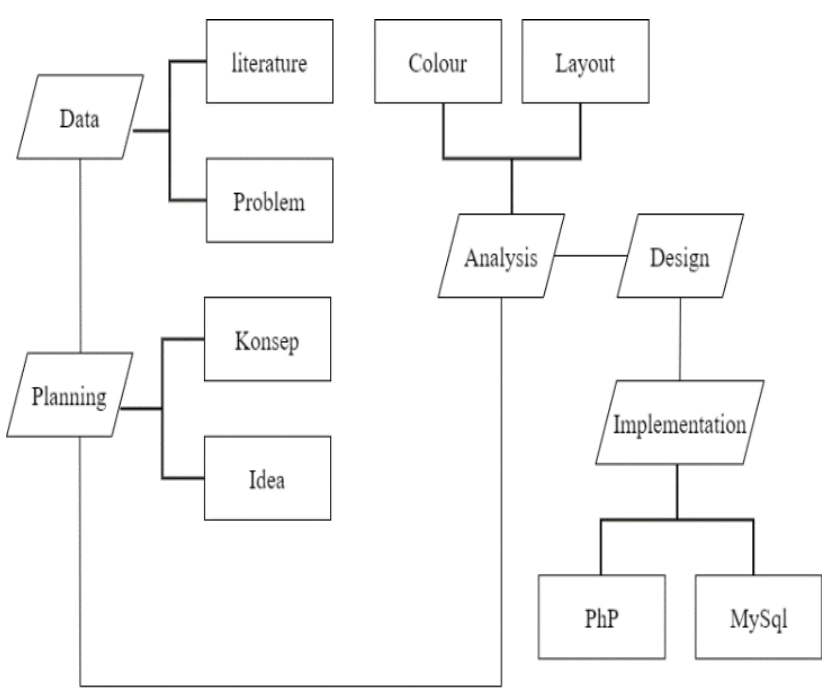

Figure 3. Website creation planning diagram

From Figure 3, it can be analyzed that there are some processes that will be conducted, i.e.,

1. Data collection.

The data collection is carried out to identify problems that occur in 27 Ilir mini garden and Sungai Sekanak River. In this stage, the supporting literature was searched and added.

2. Planning,

Planning is useful to determine the concepts and the ideas on a real-time human activity recognition website.

3. Analysis.

The analysis process is carried out in the form of color selection and layout of the website

4. Design.

At the design stage, the website design process is carried out with the existing analysis stage.

5. Implementation.

At the implementation stage, the website syntax is made for a real-time human activity recognition system using machine learning-based image processing.

\subsection{Data Analysis}

\subsubsection{Architecture}

Based on the existing problems, several databases need to be prepared for the website creation process. Every information displayed on 
the website has its database. It is intended to make easy the researcher to describe an architectural design analysis. The architecture is shown in Figure 4.

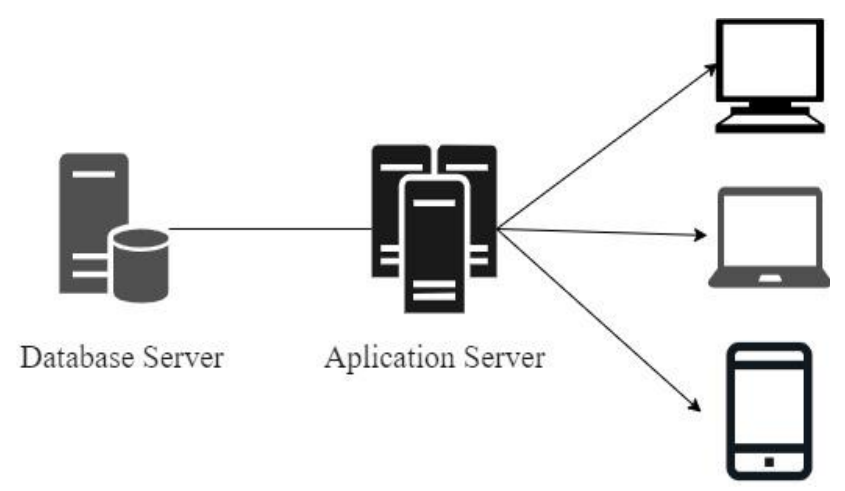

Figure 4. Application Architecture

The database used in the database server is phpMyAdmin, while the server application uses IIS or Internet Information Services or Internet Information Server in managing the webserver. The website application used by the user is Visual Studio Code which is structured between controller, model, and view. When a user accesses a website application, the application server will load the website interface and retrieve data from the database server. Through the website interface that has been loaded by the application server through the browser, users who act as admins can manage data both, for instance, creating, storing, deleting, and editing data on the website. In addition, admins users can save the data to the database, while the ordinary users can only see the results of data that have been entered on the website.

\subsubsection{Activity and environmental monitoring analysis}

Based on the system that has been created, an observation process is carried out to see the performance of the system. The process of detecting human who have littered the surrounding can be done manually by visiting the location of the system. However, using the proposed device in this research, it is no need. This research can help the community in monitoring the activity without having to come to the location.

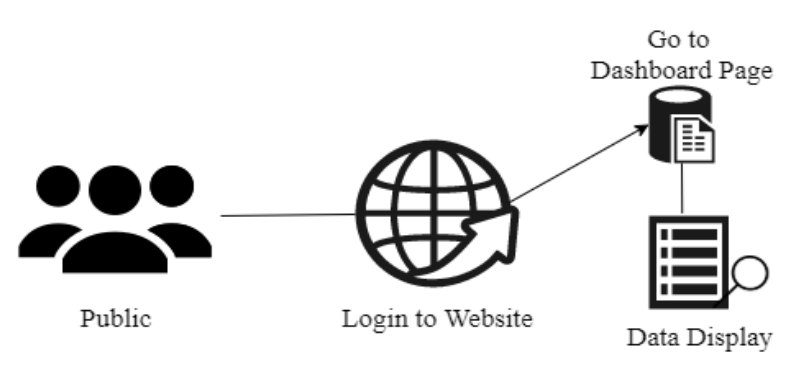

Figure 5 Activity and environmental monitoring analysis

Figure 5 shows the activity and environmental monitoring analysis. Based on Figure 5, it can be described that the public can create an active Gmail account first. Then, they should activate an email that will be sent automatically by the server. After that, the user can enter the login page. Then, the server will display a dashboard page. The users can see the display value of temperature, humidity, river water level, air quality and littering activities that have been captured by the webcam.

\subsubsection{Analysis of website needs}

Analysis of website needs is obtained based on the results of discussions and needs that must be displayed on the website, namely:

a. Create an account page for users who want to create an account.

b. Login page for users who want to login to website.

c. Forgot password page for users if they forget the password in the process of logging in to the website.

d. Activity and sensor display pages for users to see how many data values enter the server.

e. Edit page for users to correct data or errors occur.

f. Delete page for user to delete a wrong value or error

\subsection{System Design}

System design is a stage of activities carried out individually or in groups in designing or creating a system before the system is made. The system being built is aimed to fit the needs of the user's needs, related to processing, managing, and obtaining the desired information. The system design in this study has several designs, namely system design and user interface design. 


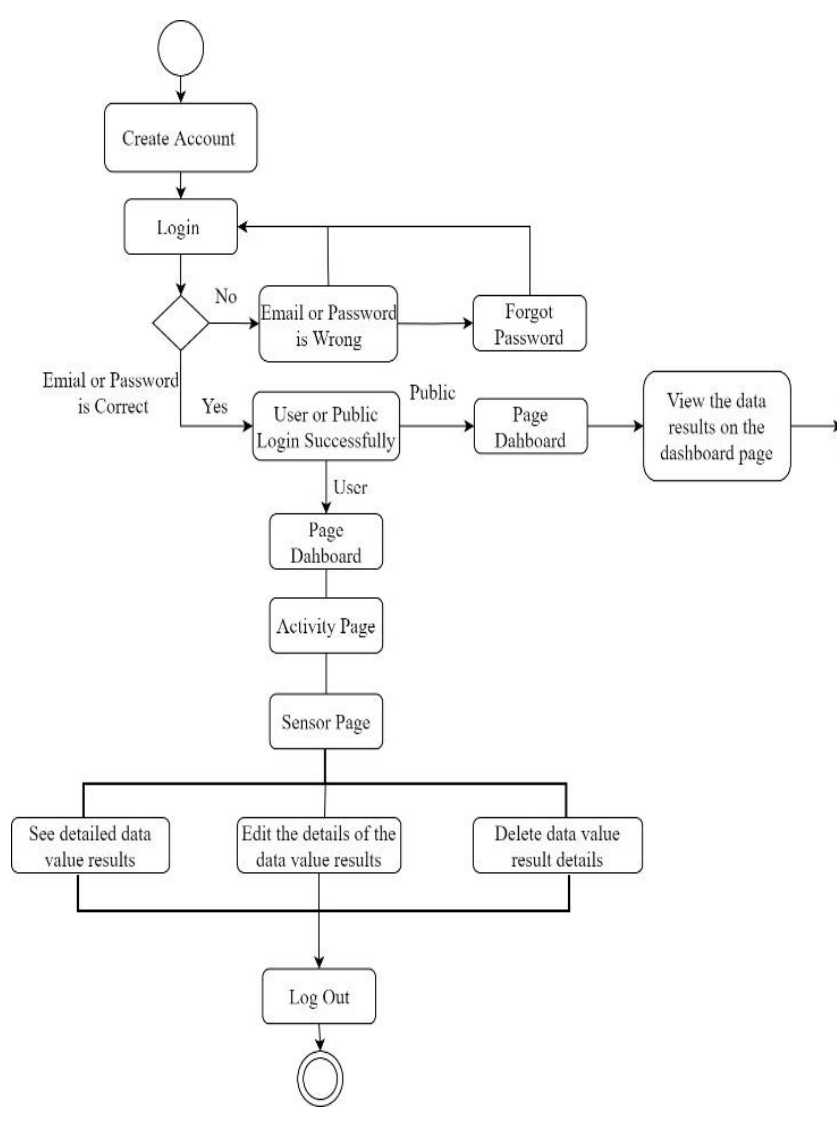

Figure 6 Activity chart

Based on the diagram in Figure 6, there are several processes for users should do so that they are able to $\log$ in to the website, namely by creating an email account first. Then, there will be an email activation notification. At this stage, the user can go to the login page. If the user forgets their email or password, they can go to the forgot password page to create a new password or enter the login page and enter the correct email and password. After that, the user can only see the results of data that have entered the website. Generally, it is displayed on the dashboard page. The user can see a page that displays a lot of data on activities. The users can add, delete, and edit activity and environmental menu on the website

Figure 7 shows the system design on computers and PCs. The system is made as complete as possible with a landing page in Figure 7 (a). It is the starting page which will briefly explain some of the functions of the tool and the location of the tool being placed. Then users will be directed to the login page as shown in Figure 7 (b) to login. If the registered email has not been registered, the users will be directed to the create an account page first as shown in Figure 7 (c). For seeing all of results of the system, the users can see on dashboard page in Figure 7 (d) to know in realtime the change of detection results

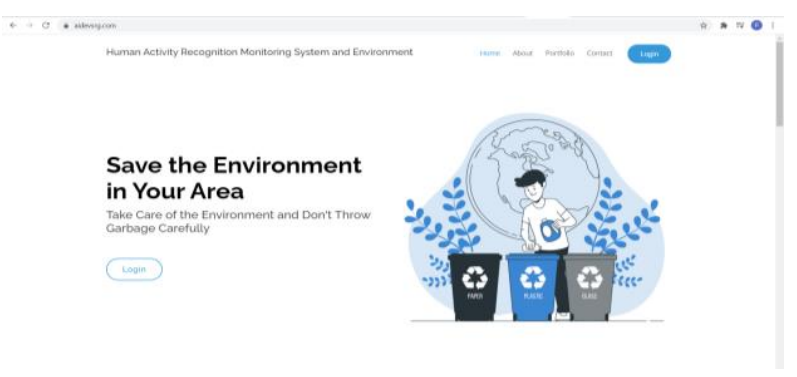

(a) Landing Page

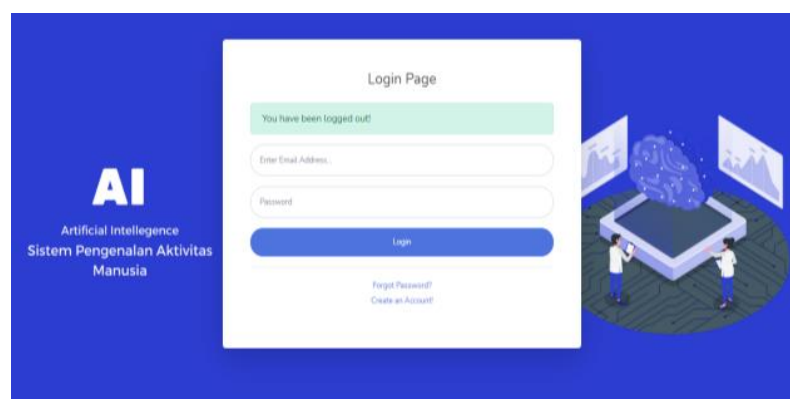

(b) Login Page

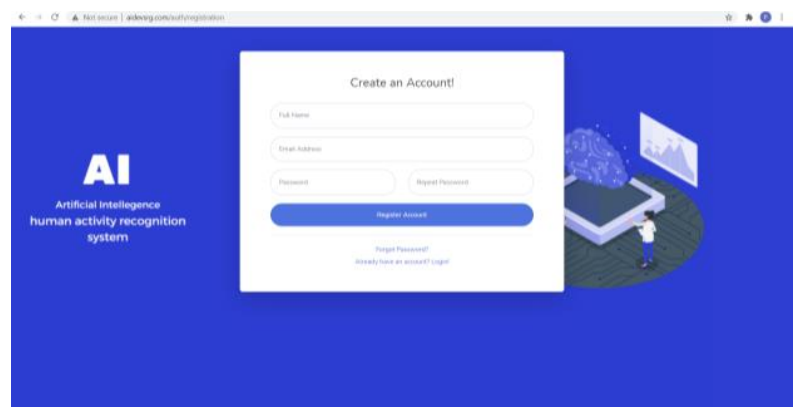

(c) Create an Account Page

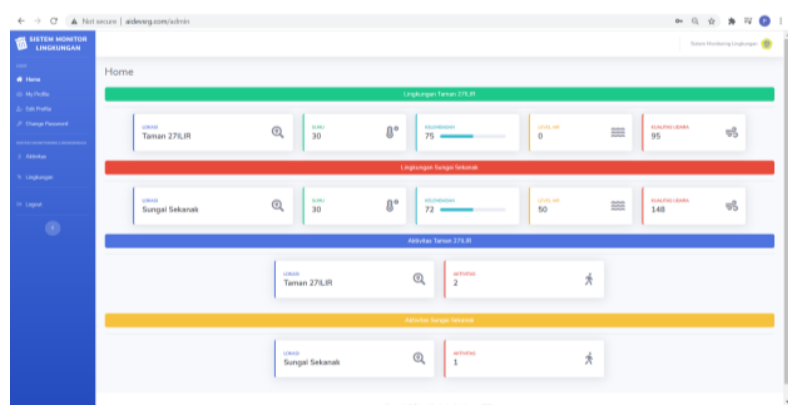

(d) Dashboard Page

Figure 7 System Design on PC or Computer 

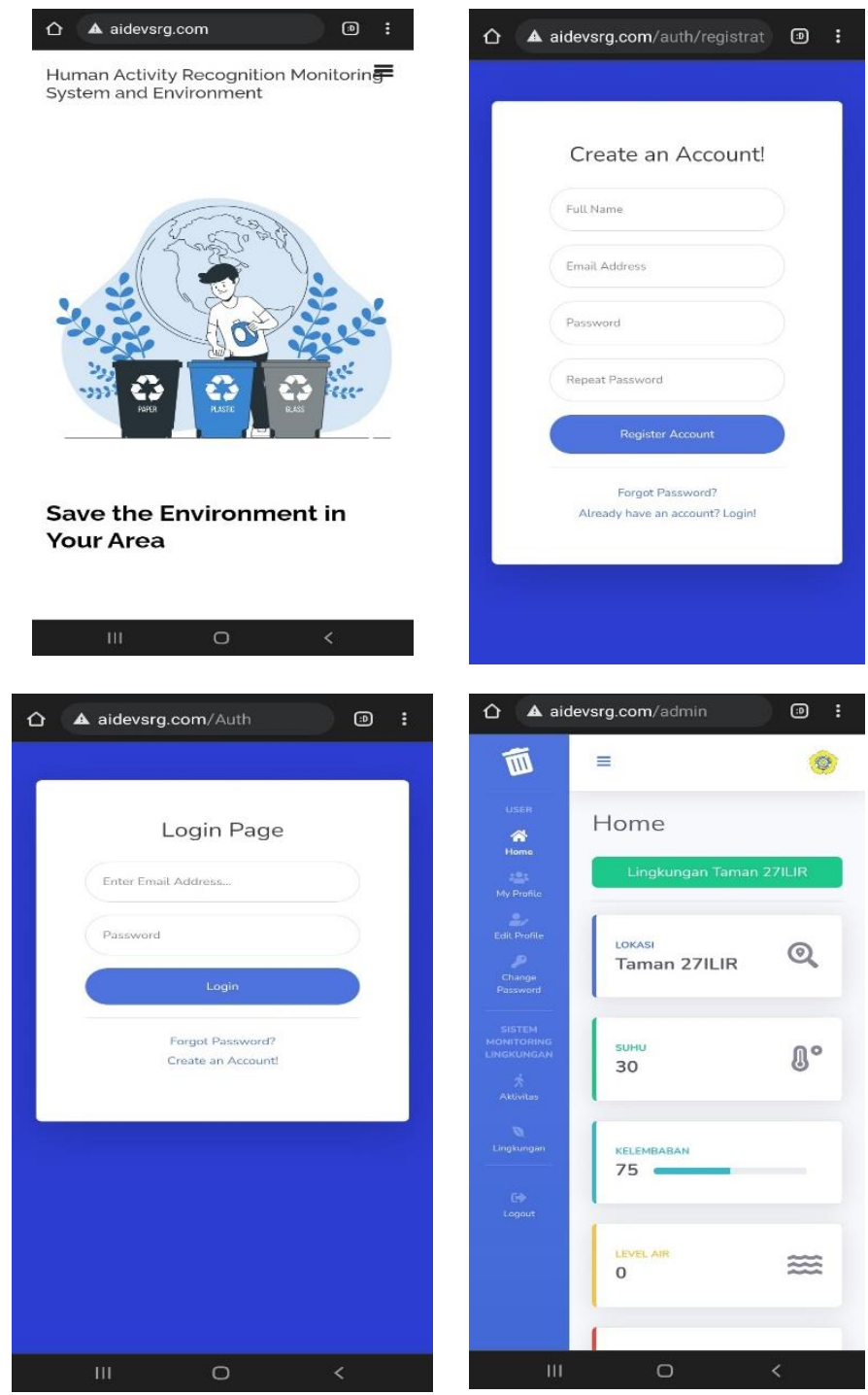

Figure 8 System Design on Mobile Phone

The design for mobile phone can be seen in Figure 8. Users must have a browser and be connected to the internet to be able to access the website that has been provided by the system. Apart from that, users who will register their email account will get an email notification from the system to activate their account as shown Figure 9

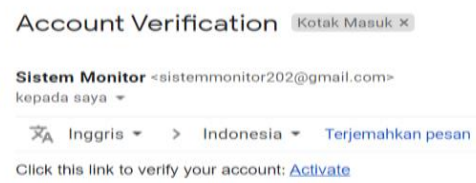

Figure 9 Account Verification
Users who have created an account, however, they forget their password, they will be directed to the forgot password page to create a new password (Figure 10)

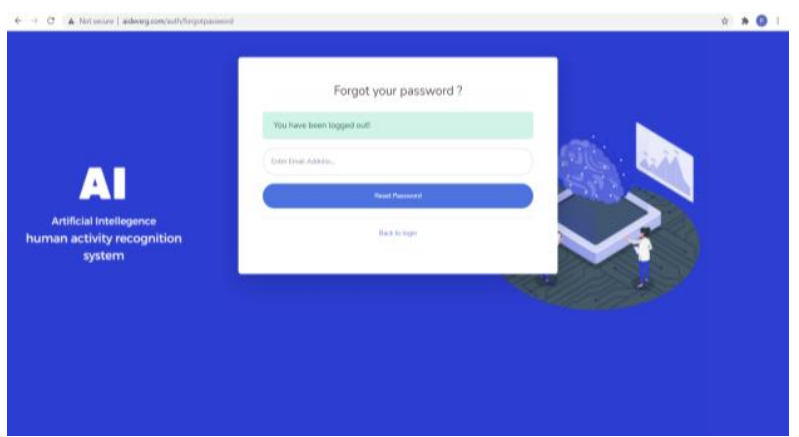

(a) Forgot password page on PC or Computer

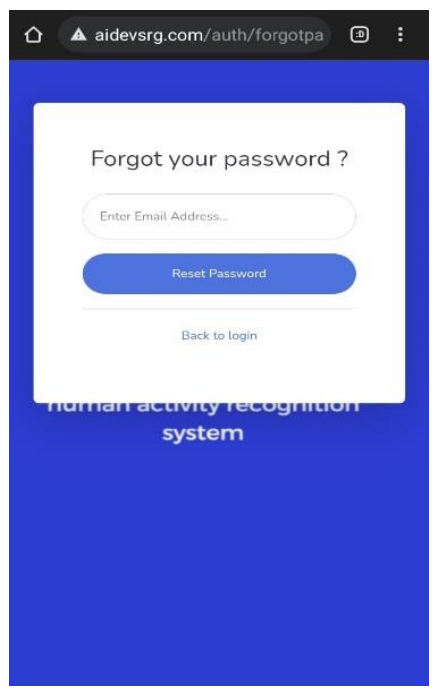

(b) Forgot password page on Mobilephone.

Figure 10 Forgot Password Page

After being directed to the forgot password page, users will also get a password reset, then users can login to the website and can see the system detection results on the dashboard (Figure 11)

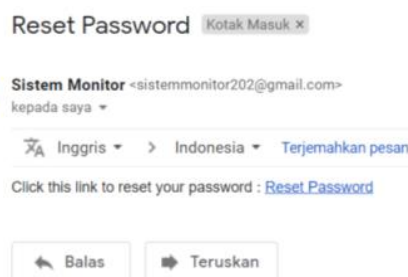

Figure 11 Reset Password 


\section{CONCLUSIONS}

The activity monitoring system can detect activities in the form of littering and detect environmental conditions such as temperature and humidity, air quality, and water level. The detection results can be seen on the system website on the system dashboard page in real-time and can also be seen directly on the system tool where the system will issue a notification sound in the form of a sound as a warning for people who have littered.

\section{REFERENCES}

[1] S. R. Prathibha, A. Hongal, and M. P. Jyothi, "IOT Based Monitoring System in Smart Agriculture," Proc. - 2017 Int. Conf. Recent Adv. Electron. Commun. Technol. ICRAECT 2017, pp. 81-84, 2017, doi: 10.1109/ICRAECT.2017.52.

[2] M. A. Zoran, R. S. Savastru, D. M. Savastru, M. N. Tautan, L. A. Baschir, and D. V. Tenciu, "Assessing the impact of air pollution and climate seasonality on COVID-19 multiwaves in Madrid, Spain," Environ. Res., vol. 203, p. 111849, 2022, doi: 10.1016/j.envres.2021.111849.

[3] S. Barua and S. D. Nath, "The impact of COVID-19 on air pollution: Evidence from global data," J. Clean. Prod., vol. 298, p. 126755, 2021, doi: 10.1016/j.jclepro.2021.126755.

[4] A. F. ; Stasiškien, "COVID-19 and Air Pollution: Measuring Pandemic Impact to Air Quality in Five European Countries Akvil ' e Feiferyt e Skirien ` e * and Žaneta Stasiškien e Citation: Skirien ' e," 2021, [Online]. Available: https://doi.org/10.3390/atmos1203029.

[5] W. Caesarendra and D. Ph, "Applied Machine Learning and Deep Learning in Mechanical and Biomedical Engineering."

[6] F. Dařena and F. Gotter, "Technological Development and Its Effect on IT Operations Cost and Environmental Impact," Int. J. Sustain. Eng., vol. 14, no. 3, pp. 190-201, 2021, doi: 10.1080/19397038.2020.1862342.

[7] E. Cambria and G. Melfi, "Semantic outlier detection for affective commonsense reasoning and concept-level sentiment analysis," Proc. 28th Int. Florida Artif. Intell. Res. Soc. Conf. FLAIRS 2015, vol. 13, no. 10, pp. 276$281,2015$. 